\title{
COMIS V3.1 SIMULATION ENVIRONMENT FOR MULTIZONE AIR FLOW AND POLLUTANT TRANSPORT MODELLING
}

\author{
Viktor Dorer (1), Anne Haas (1), Werner Keilholz (2), Roger Pelletret (2), Andreas Weber (1)
}

(1) Energy Systems / Building Equipment Section, EMPA

Überlandstrasse 129, 8600 Dübendorf, Switzerland

(2) Software Development \& Software Certification, CSTB

BP 209, 06904 Sophia Antipolis, France

\begin{abstract}
COMIS simulates multizone airflow and pollutant transport. It has been developed in an international context at LBNL and within IEA Annex 23. At the end of Annex 23, EMPA took over the coordination of further developments, and - together with CSTB the maintenance of COMIS. In January 2001, the "COMIS v3.1 with IISiBat v2.4" package was released, and is available now from CSTB. In this paper, the main features of the COMIS simulation engine, and the latest improvements are presented. An example demonstrates the use of COMIS. Pollutant transport and impact evaluation with the new version are discussed. The coupling of COMIS with the thermal simulation program TRNSYS is discussed.
\end{abstract}

\section{$\underline{\text { INTRODUCTION }}$}

\section{History of COMIS}

COMIS (Conjunction Of Multizone Infiltration Specialists) was developed in 1988-89 by ten scientists from nine countries, during a twelve-month workshop hosted by the Lawrence Berkeley National Laboratory (LBNL). COMIS is a multizone air infiltration, ventilation and contaminant transport simulation program

In 1990 the Executive Committee of the International Energy Agency's Buildings and Community Systems Agreement instituted a working group focusing on multizone air flow modeling (Annex 23, [11]). Annex 23 was supported between 1990 and 1996 by nine participating nations: Belgium, Canada, France, Greece, Italy, Japan, Switzerland, The Netherlands, and USA. Its objectives were to study the physical phenomena causing air flow and pollutant transport in multizone buildings, develop numerical modules to be integrated in the COMIS multizone air flow modeling system, and evaluate the COMIS code. Measured data from existing buildings from more than ten countries were used to check the simulation results. Last but not least, user interfaces were developed to facilitate the use and to ease the dissemination of COMIS.

The major products of IEA Annex 23 are:

- COMIS 3.0 with graphical IISiBat/COMIS user interface, COMERL user interface

- User Guides for COMIS, IISiBat/COMIS and COMERL

- $\quad$ Annex 23 Report "Evaluation of COMIS" [5,6]

- Special Issue of the Journal "Energy and Buildings" [4]

- COMIS Sample Runs [9]

Annex 23 was dissolved at the end of 1997. The programs developed within the frame of Annex 23 will partially be maintained by participating countries. The maintenance of the official COMIS 3.0 code was handed over to the Swiss Federal Laboratories for Materials Testing and Research (EMPA) in 1998.

\section{COMIS v3.1 Package}

EMPA has taken the initiative to update COMIS. Over the last year, CSTB and EMPA have developed a commercial software package based on COMIS, COMIS v3.1 with IISiBat v2.4, integrating at the same time important contributions from Lawrence Berkeley National Laboratory (LBNL), Norwegian Building Research Institute (NBI), and The Netherlands Organisation for Applied Scientific Research (TNO).

With this software package, a commercial product is available for the first time in COMIS history. Hopefully this move will not only allow to continue to maintain and develop COMIS, but also to provide a more coherent, debugged and maintained version of the software than was the case in the past. 

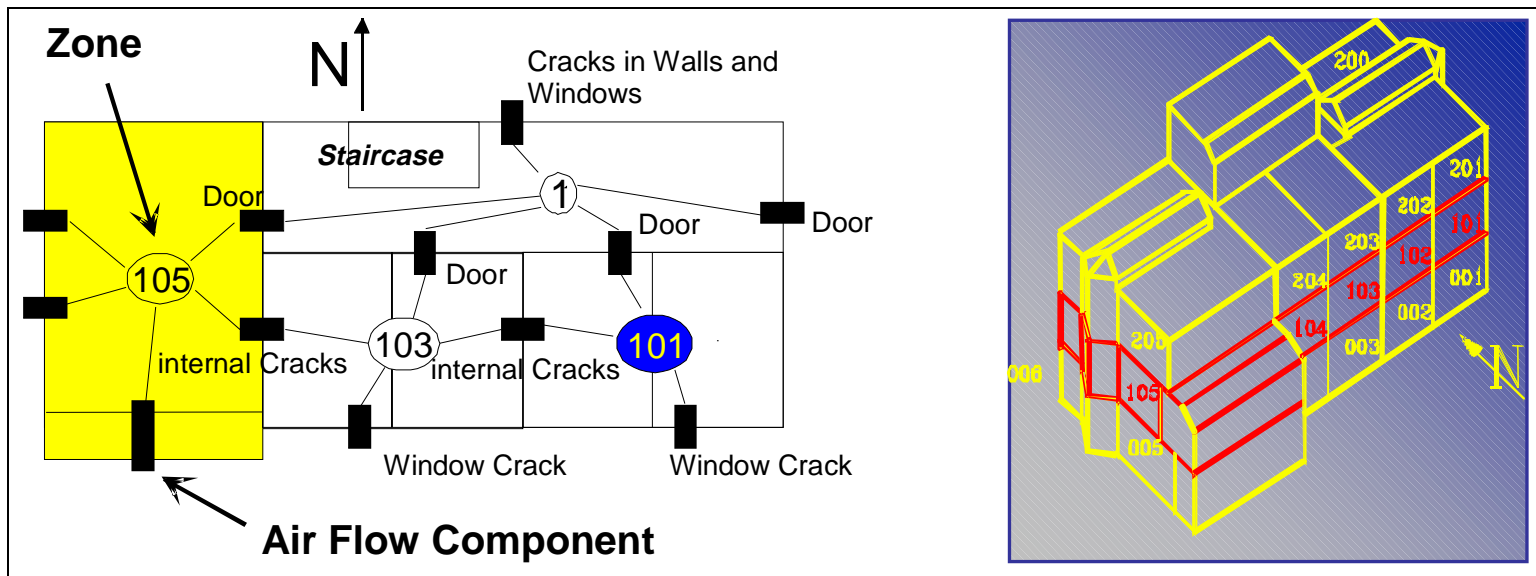

Figure 1: Floor plan of a multistorey office building with a section of the air flow network, consisting of nodes (zones) which are connected by air flow conductances. The location of the zones in the building is shown to the right. Among others, measurements and COMIS simulations of this building were used to evaluate COMIS [5,6].

The new version of COMIS has been presented during a workshop at EMPA in January 2001. The software can now be ordered from CSTB via the following WEB site:

http://software.cstb.fr

The free version of COMIS, COMIS 3.0, is still available on that site for download; it will, however, no longer be maintained.

\section{COMIS v3.1 SIMULATION ENGINE}

\section{The COMIS Model}

COMIS is based on a node model of a building (see Figure 1). It is assumed that each zone is homogeneous, and can be represented by a node with single values for temperature, pressure, and possibly for each pollutant concentration. The nodes are linked by non linear conductances, modelling the air paths (air flow components like cracks, openings, ducts, etc.). Pressure coefficients, relating the wind pressure at the building to the wind velocity, can be attributed to external nodes. Not only wind effect, but also buoyancy resulting from temperature and air composition differences, as well as flows induced by fans, are taken into account. Using air mass conservation, a system of non linear equations is built and solved.

\section{COMIS Files}

COMIS uses the files shown in Figure 2 for input, output, and temporary storage. The program can be launched in stand alone mode from a command window under the Windows operating system. In version 3.1 , the command line syntax was adapted so that the COMIS set file is not needed any more for usual simulation runs. The only files that inevitably must exist to run COMIS are the executable and an input file (CIF-file). For convenience, schedules can be defined in separate files and referenced in the CIFfile. When starting a simulation run, the schedules are first read by the executable. The events are sorted with time and stored in temporary files (No. 3 and 4 in Figure 2).

The type and amount of output can be chosen. Several output files with listings, eventually error messages, tables for spreadsheet postprocessing and histograms are available.

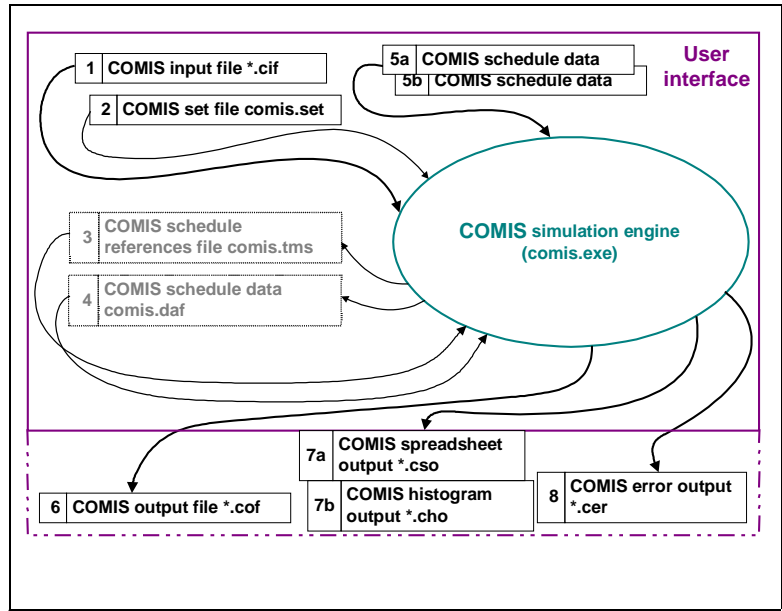

Figure 2: COMIS files.

\section{COMIS Simulation Time Steps}

Schedule events (e.g. a change in outside temperature) trigger the calculation of the network solving. The number of time steps in a COMIS simulation is determined by the number of unique points in time of the scheduled events. During one time step, the driving forces and boundary conditions 
are assumed to be constant. That means, air flow calculation is a steady state simulation. Only the pollutant transport is calculated with a dynamic model using an internal subdivision of the timesteps given by the schedule events. Additional concentration output between schedule events can be enforced. For establishing COMIS histograms the internal pollutant model time step is used.

\section{COMIS Elements}

The simulation is controlled by a text-based input file (CIF-file). An excerpt of a CIF-file is shown in Figure 3. A data section consists of a keyword (here $\&-W I)$ followed by a header - a comment explainig the expected input - and data sets (here starting with $\star W I$ ) that define elements to be used in the simulation run.

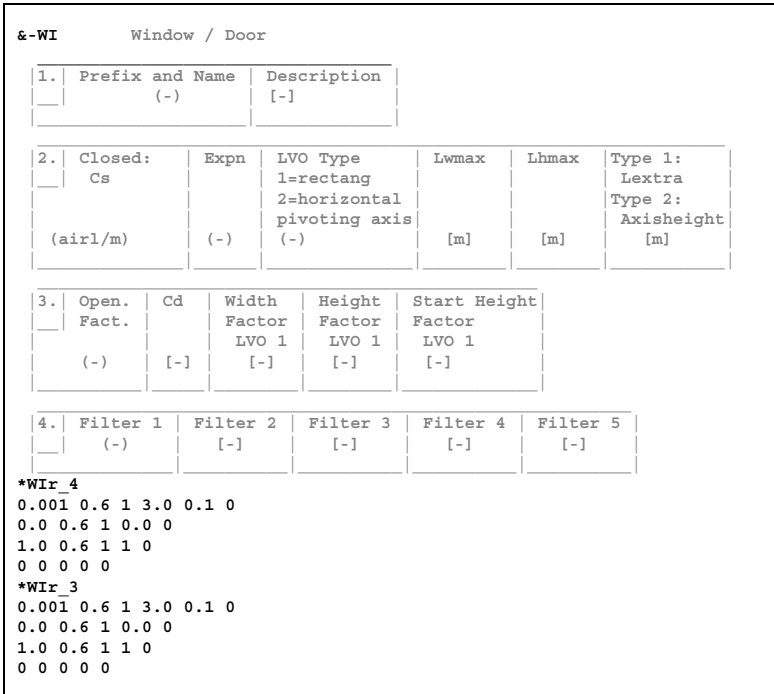

Figure 3: Excerpt from a COMIS input file. The data section starts with the keyword \&-WI. Comments and headers (light grey) may optionally be used for documentation. Two window data sets are defined in the example.

The keywords cover the following subjects:

- Project description

- Network description

- Schedules

- Building description

- Environment description

- Pollutant data

- Occupant data

The network description contains the largest number of keywords:

- Airflow components: crack, fan, duct, window, flow controller, test data
- Zones, zone characteristics:

zones and external nodes, layers, pollutants, thermal characteristics

- Network links

Schedules can be used for:

- Airflow components:

fan RPM, window opening factor

- Zones:

temperature, humidity, pollutant sink and source strength, occupancy

- Meteorological data

- Outside pollutant concentration

\section{Changes from COMIS 3.0 to COMIS v3.1}

Many valuable features were included in the code within IEA Annex 23. The underlying physical models were evaluated. However, implementing many new models led to errors and inconsistencies mainly in the logical structure of the program. Not all parts were working properly, and the consistency between code and COMIS user guide had diminished noticeably. With the list of bugs and other inadequacies in the code getting longer, there was a strong need to further improve the COMIS product.

Besides a large amount of bugfixes, major changes include

- control parameter section: parameters have been defined consistently; a new, robust solver has been implemented (see [7])

- sections concerning pollutants and occupants have been reorganised and improved (and many bugs eliminated)

- error messages: many new COMIS error messages to avoid program crashes with Fortran errors; existing messages improved

- input checks extended

At the same time, the User Guide has undergone a major revision. Additional information can be found in $[2,3,9]$.

Some features of the pollutant and occupant models are demonstrated in the example of a factory building below.

\section{IISiBat v2.4 USER INTERFACE}

The User Interface has been upgraded to version 2.4 to reflect the changes in the simulation engine and to fix some known bugs. The functionality of the IISiBat User Interface as described in [8] has been retained.

Modelling with IISiBat v2.4 is demonstrated in the example of a factory below. 


\section{EXAMPLE - VOC LOADS}

\section{Factory building}

A factory building consists of two spaces

- a hall with mechanical extract ventilation for combined abrasive and chemical treatment and subsequent bonding,

- $\quad$ and a naturally ventilated assembly hall.

The floor plan and the side view of the factory including the airflow network to be modelled are sketched in Figure 4. Figure 5 shows the representation on the Assembly Panel of the IISiBat user interface.

VOC's (Toluol) are released during chemical cleaning of bonding surfaces. The extract system is designed on the basis of the steady-state concentration determined for the maximum source strength and considering the mechanical extract ventilation only (no air exchange with the assembly hall). This concentration must be kept below the threshold concentration (TLV), which is set to $300 \mathrm{mg} / \mathrm{kg}$ in this example.
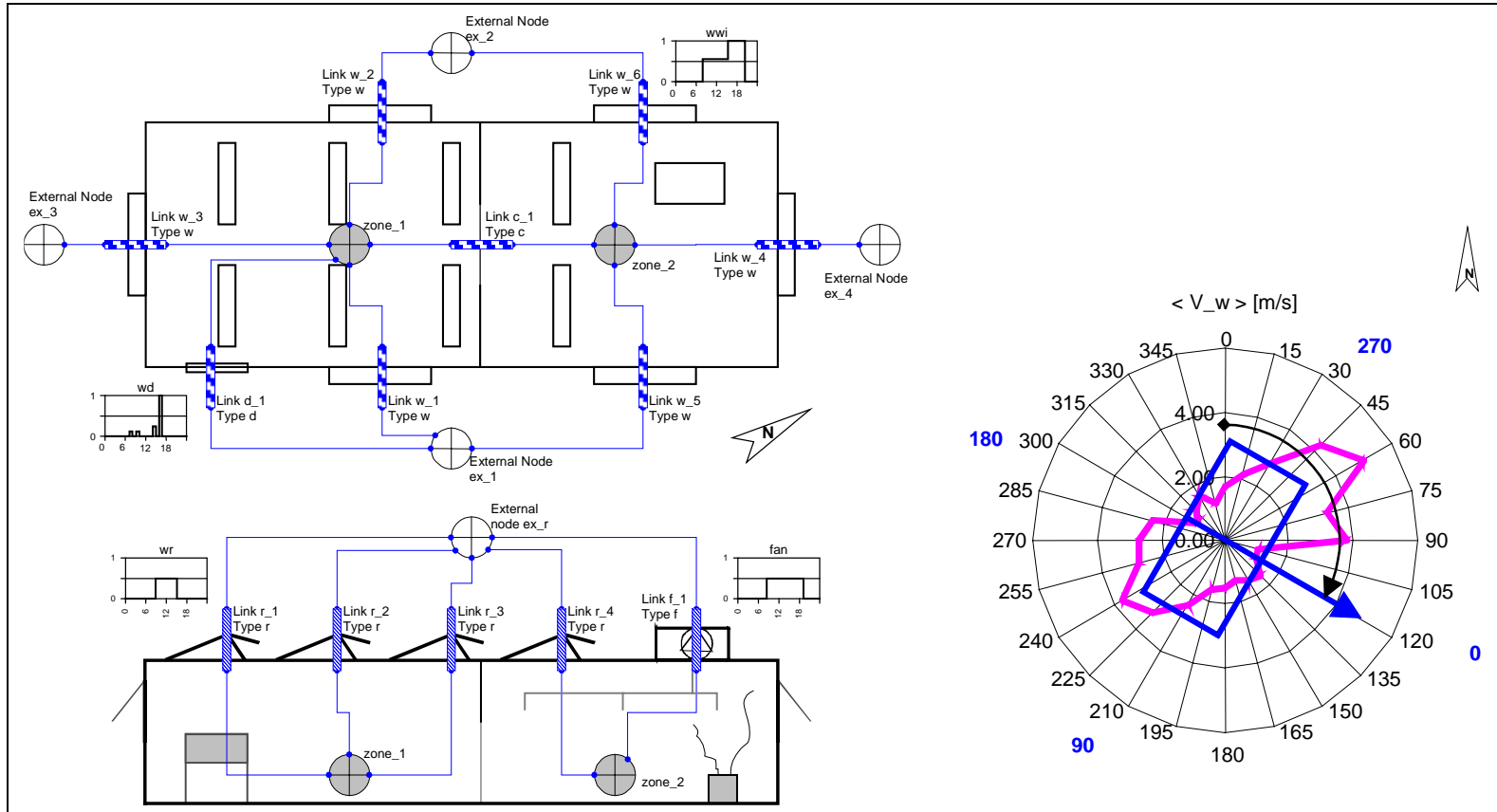

Figure 4: (Left) Floor plan and side view of the factory building including the airflow network to be modelled. (Right) Polar diagram of wind speed data used for the simulation, and building orientation (outer values: angles relative to building axes).

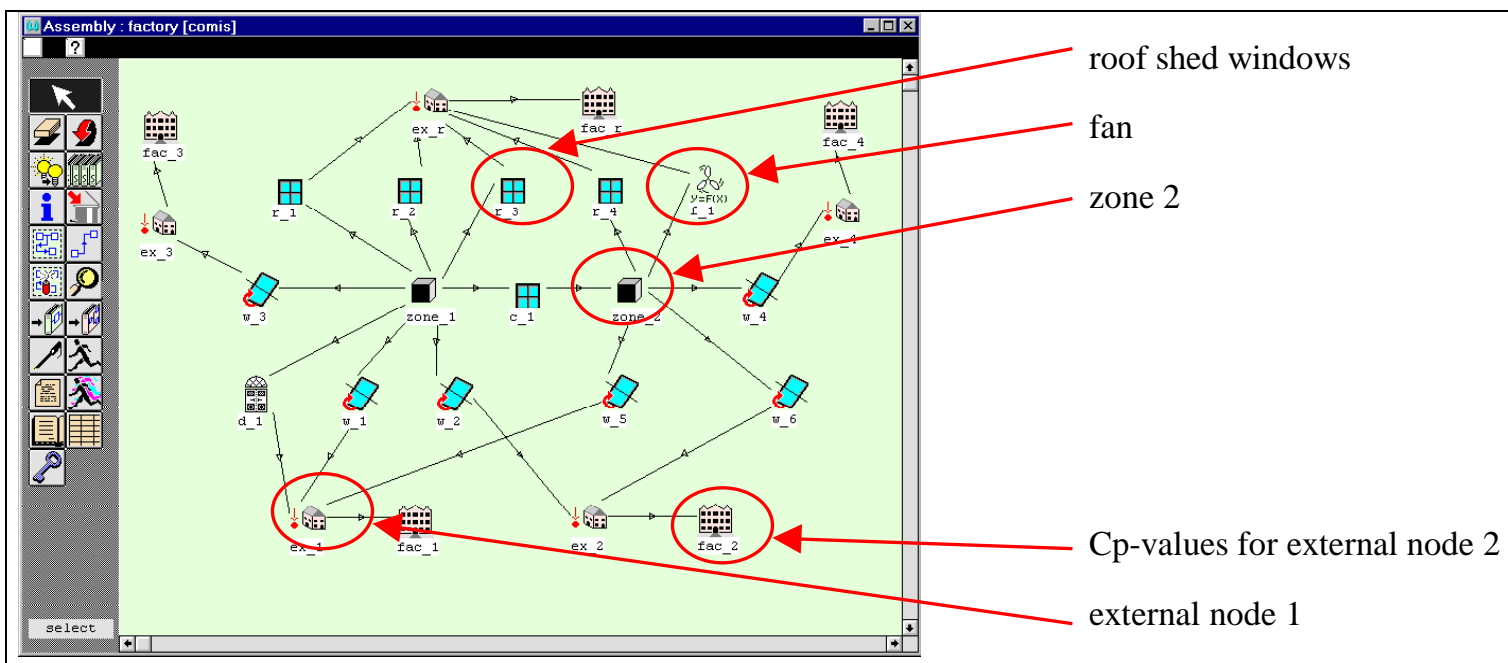

Figure 5: Representation of the airflow network of the factory building on the Assembly Panel of the IISiBat user interface. 


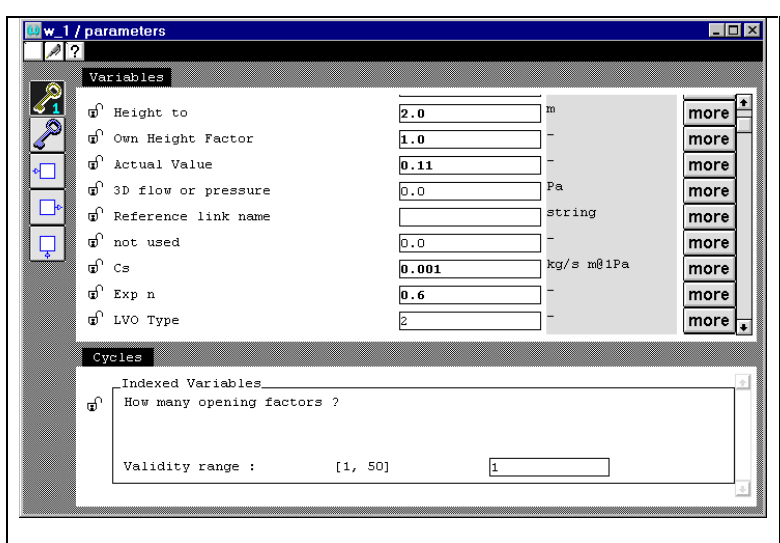

Figure 6: A click on the upper part of the window $w_{-} 1$ icon on the Assembly Panel in Figure 5 reveals the parameters of this link and of the airflow component.

\section{Problem}

The cross-contamination of the assembly hall by VOC's from the chemical cleaning and bonding process in the treatment hall shall be determined. The pollutant loads that workers experience shall be evaluated.

\section{Model}

The factory is modelled as a two-zone network with door, horizontally pivoted windows and roof shed windows as air flow elements. The mechanical extract system is simply modelled with one additional air flow component, a fan. This is sufficient if the emphasis lies on pollution transport, and not on the layout of the extract ventilation system.

Wind pressure coefficient data are taken from literature [1] for a simple rectangular building shape, surrounded by buildings of equal height.

The simulation model of the network is built on the Assembly Panel (Figure 5). Parameters and schedules are associated with the elements of the network as shown in Figures 6 and 7.

\section{Schedules}

The simulation is made for one month. A weather file with hourly data for moderate climate conditions is chosen (April in Zuerich, Switzerland). The wind speed and direction data for that period are given on the right side of Figure 4. In the example, hourly schedules with 24 schedule events (see example in Figure 8), are used for building parameters like window opening or VOC source strength. These schedules are reused for all days in the simulation

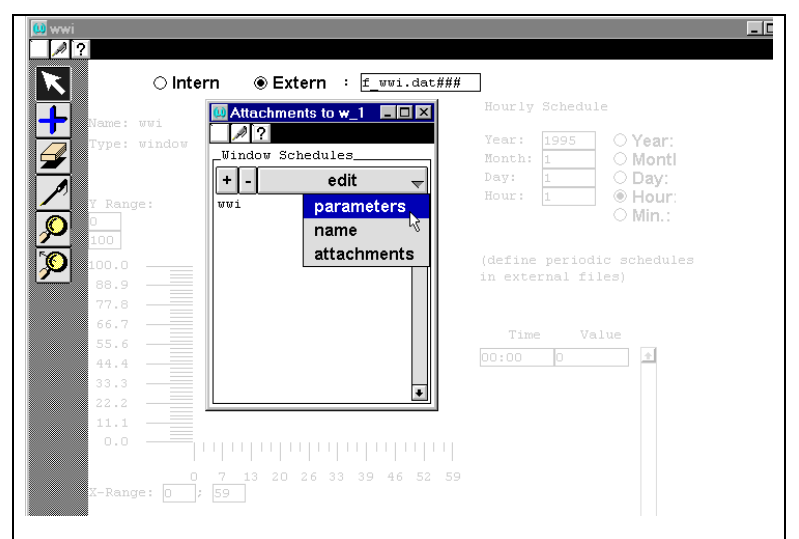

Figure 7: A click on the lower part of the window $w_{-} 1$ icon on the Assembly Panel in Figure 5 reveals the attachments of this link. A schedule 'wwi' for the opening factor of the window $w_{-} l$ is input under parameters. The schedule is read from the external file 'f_wwi.dat' (Figure 8).

period (no weekend). This results in a simulation with equal time steps of one hour.

Working hours are from 7 am to $6 \mathrm{pm}$. The fan is running during working hours. Values for air temperatures are taken from simple thermal modelling estimates. Window opening and pollutant source strength schedules are fixed according to usual working operation, adapted to the one-hour simulation time step. The scheduled values are shown in Figures 9 and 10.

\begin{tabular}{|ll|}
\hline $00: 00$ & 0 \\
$01: 00$ & 0 \\
$02: 00$ & 0 \\
$03: 00$ & 0 \\
$04: 00$ & 0 \\
$05: 00$ & 0 \\
$06: 00$ & 0 \\
$07: 00$ & 0.11 \\
$08: 00$ & 0.11 \\
$09: 00$ & 0.11 \\
$10: 00$ & 0.11 \\
$11: 00$ & 0.11 \\
$12: 00$ & 0.11 \\
$13: 00$ & 0.11 \\
$14: 00$ & 0.11 \\
$15: 00$ & 0.11 \\
$16: 00$ & 0.11 \\
$17: 00$ & 0.11 \\
$18: 00$ & 0.11 \\
$19: 00$ & 0 \\
$20: 00$ & 0 \\
$21: 00$ & 0 \\
$22: 00$ & 0 \\
$23: 00$ & 0 \\
\hline
\end{tabular}

Figure 8: COMIS window schedule 'f_wwi.dat'. For each time entry an opening factor is given. A schedule value is used until the time the next value is given or until the end of the simulation. Schedules like this - with time entry, but no date - are reused for all days within the simulation period. 


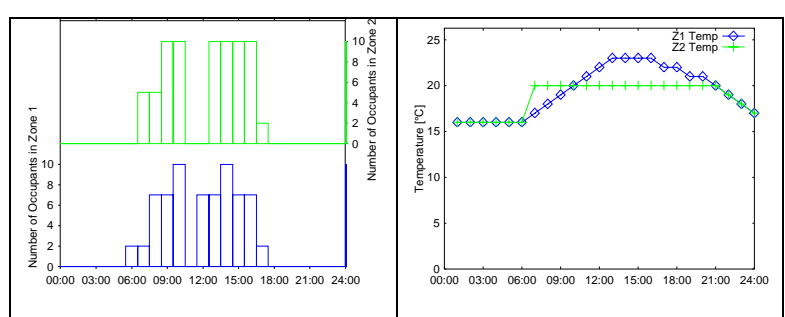

Figure 9: (Left) Number of occupants for zone 1 (lower), and zone 2 (upper).

(Right) Temperature for zone $1(-\diamond-)$, and zone 2 $(-+-)$.

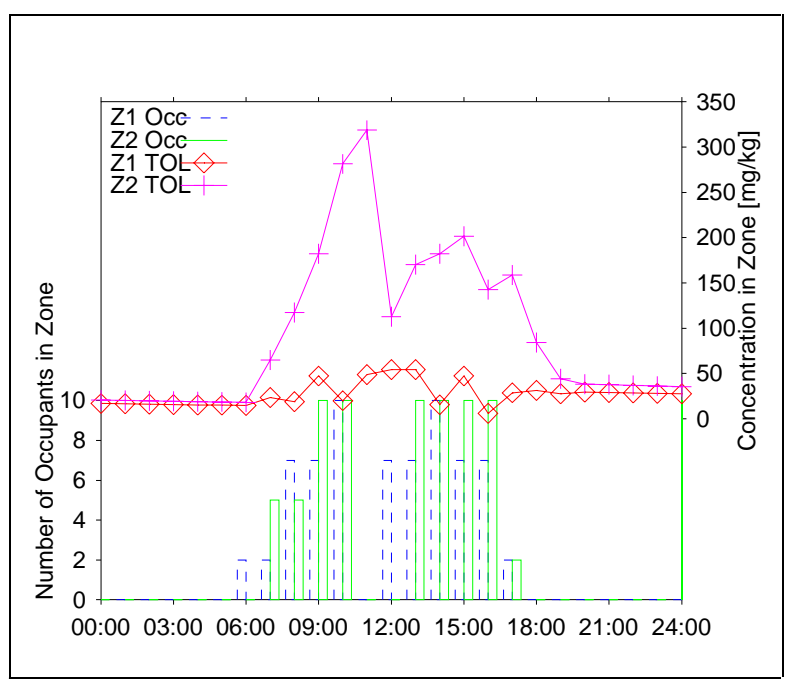

Figure 11: (Upper) Toluol concentration for zone $1(-\diamond-)$ and zone 2 (-+-) for one typical day. (Lower) number of occupants in zone 1 (dashed) and zone 2 (solid).

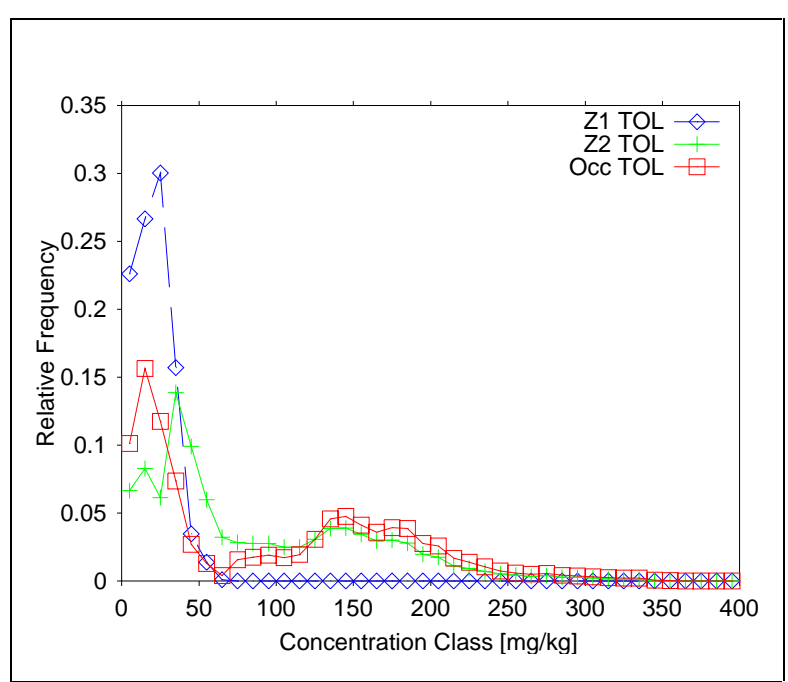

Figure 13: Relative frequency of Toluol concentration for zone $1\left(-\nabla_{-}\right)$, zone $2(-+-)$ and occupants (-口-).

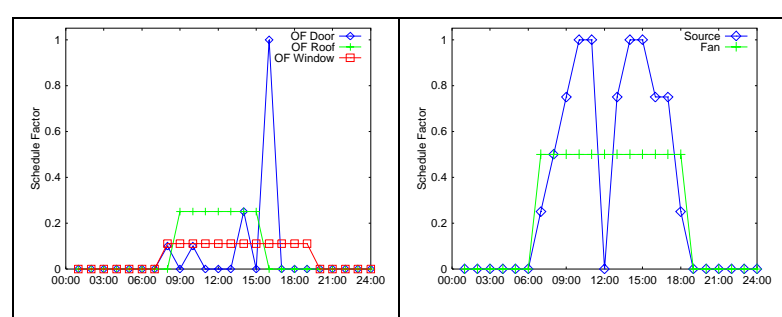

Figure 10: (Left) Opening factor for door $(-\diamond-)$, roof sheds (-+-) and windows (-口-).

(Right) Toluol source strength (- -$)$, and fan operation (-+-).

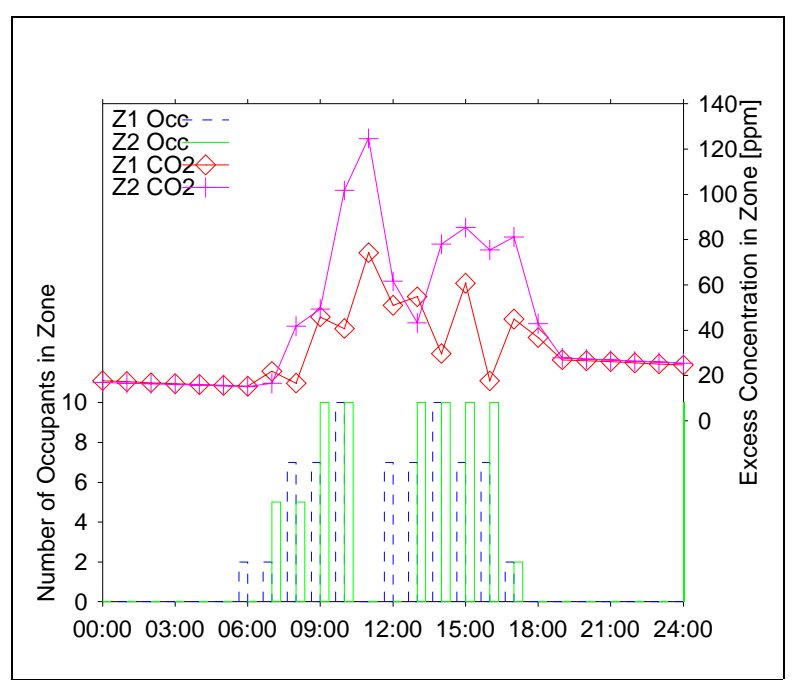

Figure 12: (Upper) $\mathrm{CO}_{2}$ concentration for zone $1\left(-\diamond_{-}\right)$and zone 2 (-+-)) for one typical day. (Lower) number of occupants in zone 1 (dashed) and zone 2 (solid).

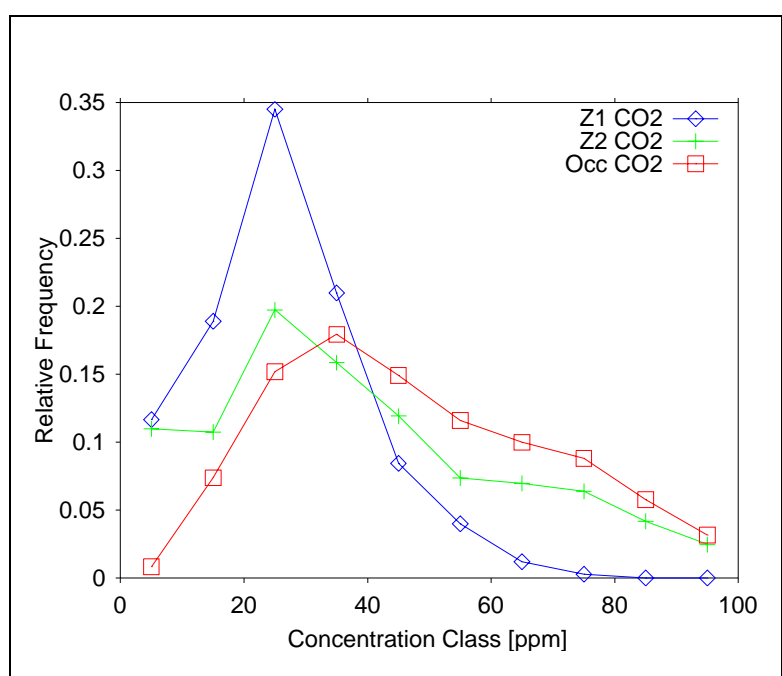

Figure 14: Relative frequency of $\mathrm{CO}_{2}$ concentration for zone $1\left(-\nabla_{-}\right)$, zone $2(-+-)$ and occupants $\left(-\square^{-}\right)$. 


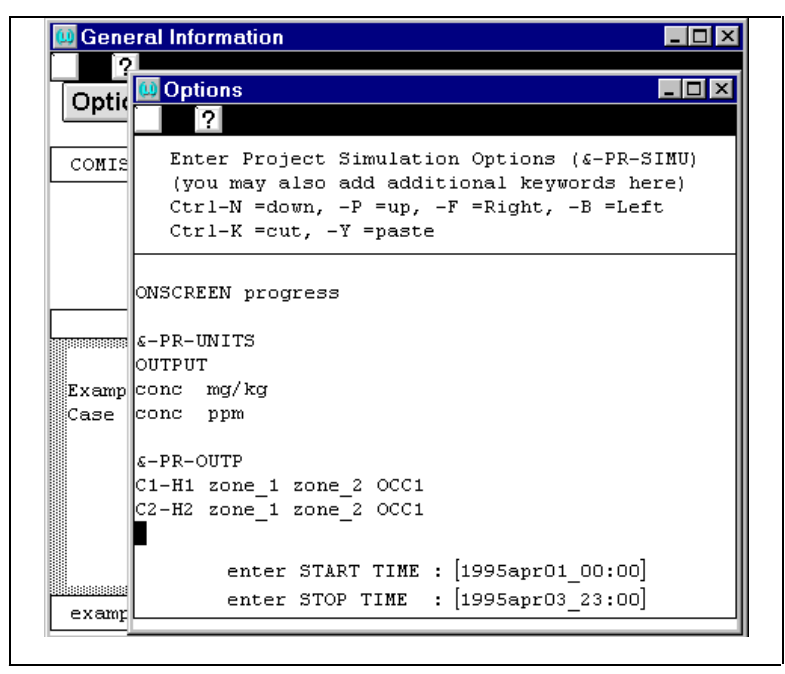

Figure 15: The Options window can be used to define input for COMIS keywords not known by IISiBat. In this example, different output units are assigned to the pollutants, and concentration histogram output for zones and occupants is defined.

\section{The COMIS histogram}

If pollutant transport is activated in the simulation, the internal pollutant model time step is used for establishing COMIS histograms. High resolution frequency distributions can thus be obtained without increasing the number of simulation time steps.

Frequency distributions for occupant types instead of zones can be defined. This occupant weighted frequency distribution counts zone quantities like the pollutant concentration multiply depending on the number of occupants. I.e., if there are no occupants in a zone, the pollutant concentration of that zone is disregarded. The concentration in a zone with five occupants would be counted five times. This means that the occupant type acts as a sensor (besides possibly being a pollutant source).

COMIS histogram output (histogram type number 2) for the concentration of $\mathrm{CO}_{2}$ (concentration of pollutant number 2, C2) is listed in Figure 16. The output includes zones zone 1 and zone 2, and occupant type Occ1; each in one column. For the VOC concentration, another unit and forty classes (instead of ten) are used. The histogram output is directed to a separate file.

\section{Results}

Figures 11 and 12 show the number of occupants and the concentrations (left: Toluol; right: $\mathrm{CO}_{2}$ ) for one typical day. Figures 13 and 14 show the resulting frequency distribution for zones and for occupants (left: Toluol; right: $\mathrm{CO}_{2}$ ). For $\mathrm{CO}_{2}$, the histogram data are additionally listed in Figure 16.

\begin{tabular}{|cccc|}
$\begin{array}{c}\text { Histogram 2 } \\
\text { ClassCenter }\end{array}$ & $\begin{array}{c}\text { Classes From } \\
\text { C2-z1 }\end{array}$ & $\begin{array}{c}5.00 \mathrm{E}+00 \\
\mathrm{C} 2-\mathrm{z} 2\end{array}$ & $\begin{array}{c}\mathrm{TO} \\
\mathrm{C} 2-\mathrm{OCC} 1\end{array}$ \\
& $\mathrm{ppm}$ & $\mathrm{ppm}$ \\
5.00000 & 0.11656 & 0.10980 & 0.00846 \\
15.00000 & 0.18916 & 0.10757 & 0.07388 \\
25.00000 & 0.34505 & 0.19750 & 0.15184 \\
35.00000 & 0.20995 & 0.15856 & 0.17941 \\
45.00000 & 0.08455 & 0.11927 & 0.14917 \\
55.00000 & 0.03991 & 0.07380 & 0.11617 \\
65.00000 & 0.01192 & 0.06983 & 0.09994 \\
75.00000 & 0.00274 & 0.06385 & 0.08813 \\
85.00000 & $1.7385 \mathrm{E}-04$ & 0.04182 & 0.05768 \\
95.00000 & 0.0 & 0.02479 & 0.03159 \\
below_range & 0.0 & 0.0 & 0.0 \\
over_range & 0.0 & 0.03324 & 0.04378 \\
max_freq & 0.34505 & 0.19750 & 0.17941 \\
average & 26.35961 & 41.07990 & 50.27995 \\
total_time & 2588387.8 & 2588387.8 & 15119498.0 \\
minimum & 0.0 & 0.0 & 0.45219 \\
maximum & 80.47812 & 139.67819 & 139.67819 \\
Unit_offset & 0.0 & 0.0 & 0.0 \\
Unit_mult. & $6.5828 \mathrm{E}+05$ & $6.5828 \mathrm{E}+05$ & $6.5828 \mathrm{E}+05$ \\
& & & \\
\hline
\end{tabular}

Figure 16: COMIS histogram output to file 'fac_5H2.cho'.

Occupants reside in both zones, but only during working hours and in varying numbers. Therefore the occupant-weighted frequency distribution is shifted to higher $\mathrm{CO}_{2}$ concentration values compared with the frequency distributions for the zones (where low $\mathrm{CO}_{2}$ values in the night are also counted). For Toluol, we have two peaks. The lower stems from occupants in the assembly hall, which has only crosscontamination from the bonding hall and no source. The higher peak stems from occupants working in zone 2, the bonding hall, with the higher concentrations. Like for $\mathrm{CO}_{2}$, the shift to higher concentration values for the occupant-weighted frequency distribution can be observed.

The results show that the TLV for Toluol $(300 \mathrm{mg} / \mathrm{kg}$ ) in zone 2 (bonding hall) is exceeded in the analysed time period in $0.7 \%$ of the time in the bonding hall, and in $1.1 \%$ of the total presence time for the ensemble of occupants. The concentration in zone 1 is always much lower than the TLV.

Measures to reduce peak values can now be evaluated by further simulation runs.

\section{COUPLING COMIS AND TRNSYS}

Within Annex 23 COMIS has been adapted as a TRNSYS Type called COMIS-TRNSYS Type 157. The COMIS v3.1 package includes the updated source code of Type 157, and documentation and examples of the coupling with the actual TRNSYS version 15 .

Type 157 is to be used in combination with Type 56, which is the thermal multizone building model of TRNSYS [10]. This allows for the integral determination of the heat fluxes due to transmission, radiation and convection. Interactions between 
building mass, equipment and air flows due to natural and mechanical ventilation can be studied.

At each time step in the dynamic simulation a solution is iteratively determined. In each iteration loop the room air temperature values are passed from the thermal building model Type 56 to Type 157 , which returns the respective air flow rates to Type 56 . The calculated air flow rates per room are assigned to the interzonal flows, the infiltration flows or to the flows from the ventilation system, which all are required by Type 56 .

Figure 17 shows the part of a TRNSYS model with the two Types mentioned, their data exchange, as well as links to other TRNYSYs types, and the related input and output files. Up to now, building data must be input separately in two input files for Types 56 and 157, respectively. Meteorological data and scheduled values e.g. for window openings for Type 157 are supplied via TRNSYS.

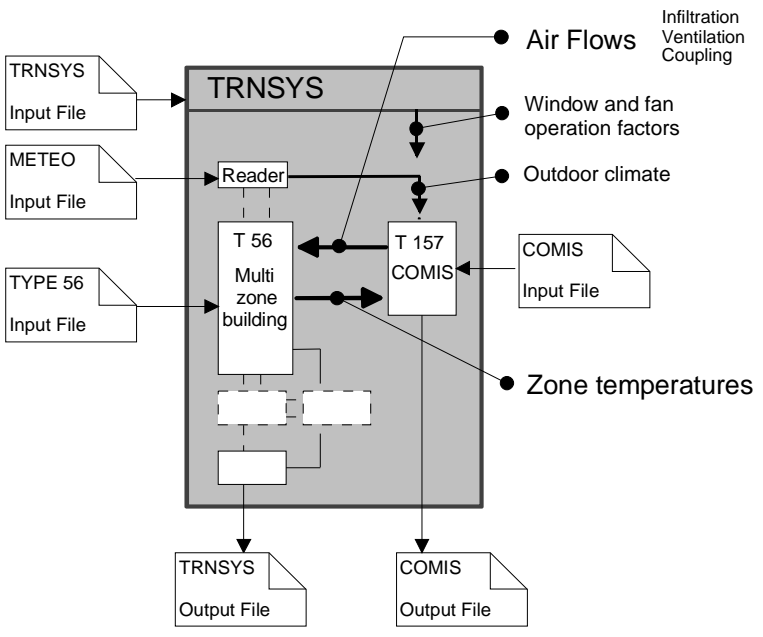

Figure 17: Integration of COMIS as Type 157 into TRNSYS. Air flow and zone temperature data are transferred between the thermal and the ventilation model.

\section{CONCLUSIONS}

With the COMIS v3.1 package, a more coherent, debugged and reliable version of the software is available.

In the future, the integration of COMIS into TRNSYS will be improved. Redundancy in data input to Types 56 and 157 will be avoided.

Further models like cowls and equation inputs, which were already developed in IEA Annex 23, should be completed, tested and implemented.

\section{REFERENCES}

[1] Orme, Malcolm, Liddament, Martin W., and Andrew Wilson: "Numerical Data for Air Infiltration \& Natural Ventilation Calculations" AIVC-TN-441994, Reprinted and Updated February 1998, Air Infiltration and Ventilation Centre, Bracknell, UK, 1998

[2] Dorer, Viktor and Andreas Weber: "Output Options for COMIS", IEA-ECB Annex 23, EMPA Dübendorf, CH, March 15, 1995

[3] Feustel, Helmut E.: "COMIS - An International Multizone Air-Flow and Contaminant Transport Model", Lawrence Berkeley National Laboratory, USA, Report LBNL-42182, 1998

[4] Feustel, Helmut E. (Editor): Energy and Buildings - Special Issue devoted to Multizone Air-Flow Modeling, Energy and Buildings, Vol. 30, No1, 1999

[5] Fürbringer, J.-M., C.-A. Roulet, and R. Borchiellini: "Evaluation of COMIS", Swiss Federal Institute of Technology, Lausanne, CH, 1996

[6] Fürbringer, J.-M., C.-A. Roulet, and R. Borchiellini: "Evaluation of COMIS - Appendices", Swiss Federal Institute of Technology, Lausanne, $\mathrm{CH}, 1996$

[7] Lorenzetti, D.M., and M.D. Sohn: "Improving Speed and Robustness of the COMIS Solver", in Proceedings, "7th International Conference on Air Distribution in Rooms" (Roomvent 2000), Elsevier, Oxford, UK, 2000

[8] Pelletret, Roger Y., and Werner P. Keilholz: "COMIS 3.0 - A new Simulation Environment for Multizone Air Flow and Pollutant Transport Modelling", in Procoodings, "5th International IBPSA Conference Building Simulation '97", Prague, CZ, 1997

[9] Phaff, J.C.: "COMIS Sample Runs", TNO Report 96-BBI-R 1086, TNO Delft, The Netherlands, 1996

[10] TRNSYS: "A Transient System Simulation Program", Solar Energy Laboratory, University of Wisconsin Madison, USA

[11] Warren, Peter: "Multizone Air Flow Modelling (COMIS)", IEA-ECB Annex 23, Document TSR-062000, ISBN 1902177155

\section{ACKNOWLEDGEMENTS}

Dave Lorenzetti (LBNL), Peter Schild (NBI), and Hans Phaff (TNO) contributed much to this new version of COMIS.

This work has been partially funded by the Centre for Energy and Sustainability in Buildings (EMPA ZEN). 